\title{
Interview
}

\section{A right upfront mantra for change management in database publishing - An interview with Thomas J. Marine of Johnson Ventures}

\section{Thomas J. Marine}

holds a BA in Journalism from Marshall University, and has been involved in publishing/pre-press environments since 1977. He is currently the Special Consultant to the owner of Johnson Ventures, Columbus, IN. Tom has been involved in DAM implementation for multichannel marketers since 1997, including 1000-pages catalogue and $300+$ page catalogues.

ABSTRACT A case study on best practices to use when implementing - database publishing solutions in a multichannel (catalogue and internet)-based environment. Learn how doing things 'Right Upfront' can improve the workflow process, the change management process and end results. Preparing for change is as important as the change itself, and possibly more important than the results, because the better the preparation, the easier the change, and consequently the higher the degree of improved results. Journal of Digital Asset Management (2009) 5, 315-328. doi:10.1057/dam.2009.19

Keywords: change management; database publishing; integrated marketing channel publishing; publishing efficiencies; publishing workflow optimization; catalogue publishing

MM: We're here with Tom Marine of Johnson Ventures. Tom - would you give us a little bit of a background in terms of your professional career?

TM: Sure. I've been in the publishing industry for more than 30 years. I started out in newspapers and quickly went into marketing. I've been focused on catalogue publishing for the last 15-plus years. I have been in charge or have been involved in large- to medium-sized catalogues that have wide national distributions everything from door-chimes to fake food, and restaurant equipment.

MM: You recently were with a company called Central Restaurant. Could you describe a little bit about the company?

TM: Central Restaurant is a wholesale equipment supplier to the restaurant industry, and also to large institutions that offer food services, selling anything from small wares like tongs or flatware to walk-in coolers and freezers.
They do multichannel marketing, utilizing both a relatively large catalogue of about 320 pages. We send it out six times a year to millions of customers and prospects throughout the United States.

MM: The nature of that business is that it constantly is on-boarding a fairly significant number of new customers?

TM: Correct. Yes. Acquiring new customers is very important for us, because of the volatility of the market.

MM: Before we go on into the specifics of that, could you give us a little bit of background on your previous engagements - specifically at Hubert?

TM: Sure. At Hubert, I was in a similar role - only it was a larger catalogue of about 1000 pages. They additionally sent out monthly catalogues to do more prospecting and targeting towards the customer. Also, to drive business back into what they called 'The Source 
Book'. That along with the online production.

At Central Restaurant, not only did I handle catalogue production, but I also handled circulation, the list procurement. That's where the differences lie between the two jobs.

MM: One of the things that I recall from our previous conversations is that at Hubert, you were instrumental in reworking their core processes around developing an integrated workflow for the print and online catalogue. Hopefully, we'll get into that a little bit more.

You've now participated in several instances of driving the internal changes around how to really integrate multichannel marketing communications, specifically, as it entails big-book catalogues.

TM: That's correct. Something we did at Hubert - which was in 1998 and 1999 - was to rework the flow of catalogue production. That also was in the early stages of getting the web online. So there were multiple reasons to do that.

Central went through a similar process. There were a few steps different, because it was 10 years later. But there are an awful lot of things that are very similar in how to approach this new, very integrated relational database situation.

I was basically the evangelist of the Hubert change, and I did that at Central. Along with that, I handled a lot of the database publishing duties for other $\mathrm{K}+\mathrm{K}$-America companies, including C\&H Distribution and Conney Safety, at the time. I was also highly involved in their integration into their publishing relational database.

MM: As we develop our master-class study of how to facilitate and/or drive these sorts of transformations - perhaps we can weave in both the Central Restaurant and Hubert story.

TM: Great.

MM: Let's start off with the catalytic event or events. What happened that required a change in your workflow? Either at Hubert or at Central Restaurant?

TM: 'Require' is a strong word. In both cases, it felt as though the onus was on the company to remain a business leader and have a best-in-class environment. Hubert did not want to not have the best systems. Central was dead-set on having a best-in-class environment in all of their different technological pieces. MM: Could you share with us where that notion comes from in the organization? TM: Central was purchased in 2006 by Johnson Ventures.

Rick Johnson is the owner. He's just one of those guys that believes that having the best in class of anything - that's where he wants to be. Now, the best in class doesn't necessarily mean it's going to be the best out there. It could mean it's just the best for the environment that the company is in at that point - looking toward the future.

An example might be an Endeca solution, a guided navigation solution for a website that is the best in class. But it's best in class for the big boys, and maybe that's not necessarily needed for a company of our size.

MM: So, with the mindset of having the bestof-class system for your particular organization, what led to the need or idea of, 'We've got to do something different'?

TM: Well, luckily, when I was hired at Hubert, actually in the interview process, I mentioned to them that I'd been looking at database publishing solutions for my previous job, which was with a newspaper circular centralized prepress group.

When I was looking at that, the company that I was with before decided not to go down that road. So I had already looked into lots of these types of solutions that would help production efficiencies.

Therefore, when I presented that to Hubert during the interview process, they were intrigued. I believe it was one of the key reasons I was hired there. Consequently, a couple of years later, they gave me the freedom to do some research. That involved at the time - going to events like Seybold and Print and ACCM - looking into the providers of these types of automated database publishing solutions or content management or DAM groups, and coming up with a solution that we felt was right for Hubert at that time.

A lot of that research I had done before Hubert I was able to utilize again - having been in the business for a while, speaking at different events. So I was able to keep my toe in the water, so to speak. 
When I came on board at Central Restaurant, it was very easy for me to jump back into research mode and take a look at all of the pieces. All of the different vendors who had been out there - many of whom were the same. That was reassuring. But also to take a look at some of the newer vendors out there, and to make a determination of whether or not those solutions might be a better fit for us.

MM: So, looking back, the idea of 'investing yourself personally in research', and developing mental maps as well as thick folders of research, you were also really investing yourself in understanding the next technology wave - in this case, database publishing.

So, not only did you find it gratifying, but it became a differentiator. The research that you did then became an attractive dimension for you as a potential employee.

TM: Yes. And it's ongoing, of course. Not only did it help me get the job at Hubert, but also Hubert then allowed me to continue my research, and to become basically an expert in the field while at Hubert. That then allowed me to broaden my wings and move on after Hubert. Although I must say, Hubert was a great place to work.

MM: So, coming from that mindset of having a best-of-class system, that also entails hiring individuals who understand what it means to be best of class, and who - in fact - are innovation leaders in and of themselves.

You demonstrate that you're an innovation leader by coming into a new engagement with a pretty deep portfolio of knowledge and research findings.

TM: Yes. I think that's a great way to put it. Absolutely.

MM: As you were there at Hubert, invested and coming in already with the idea that database publishing is the 'next wave' of innovation and technology and productivity drivers - what happens then next?

TM: Well, I think the key there is to develop a systematic way to gain buy-in with the company to be able to move forward.

What I was allowed to do at Hubert was write a white paper that depicted what database publishing could do, and was fairly in-depth on how it would affect the organization - and in some ways, the hierarchy of the organization.
It basically outlined, 'Here are the steps that we have to take'. It's not just implementation. Part of the success of database publishing involves bringing in the key vendors that are involved - to have them methodically work through a process with you, and to show the company that they understood what you were doing. That way, they could present to you, based on what you wanted out of the software.

Even before there were presentations being done, there was a lot of dialogue outlining how those presentations should be done for Hubert. MM: As you had developed the organizational strategy for how Hubert might benefit from database publishing, one of the major efforts that you undertook entailed developing an internal white paper.

The preparation of the paper allowed you to put into cogent, logical order, an organizational change - an organizational transformation story.

As you began to circulate the white paper, the white paper served as a persistent messaging object - a framework - for structuring and guiding internal conversations around how affected stakeholders could come up-to-speed with the new system.

TM: Absolutely.

MM: And then, the process of bringing stakeholders up-to-speed revealed new criteria and new needs that subsequently you wove back into the next version of the white paper.

So, the white paper was a living document that continued not only the conversation, but also the coalescence of, 'Yes. This makes sense'.

That then gave you a nice platform from which to start engaging vendors in terms of what you need from them.

So now what I'd like you to speak to next is something that I find absolutely fascinating. As I recall in 1998 or 1999 - when all of this took place - there was a conversation of, 'Maybe we ought to get a DAM'. It came back to, 'Let's figure out exactly how we produce our big-book, 900-page catalogue, and understand if there are any other inefficiencies we should work out before we actually start looking at DAMs'.

Could you take us through that process? TM: Absolutely. That was the fun part, really. 
What was intriguing was that it was apparent that all of the people involved in producing the catalogue had probably never been in the same room at the same time, before. Therefore, there were lots of big revelations once we sat down together.

We got 15 stakeholders in a meeting - people from groups that touched the catalogue to people who participated in the production of the catalogue - everyone from merchandisers to graphic artists to IT people. Also, we had some fairly significant shareholders, like a VP of Marketing who was there for many of the meetings.

But basically we had 15 people, and over a 9-month period, we met twice a week for half a day - initially to define the workflow that was currently in place. The direction of the meeting was very specific. We were not there to change anything at that point. We were only there to identify and to bring artefacts. To make sure that everyone understood exactly what was being done now. We met in what we called the 'War Room'. It was a fairly big conference room that had windows - over half of it that we actually covered up at one point, because we simply needed more room to put stuff on the walls.

MM: As I recall, you physically mocked up each step of the workflow associated with publishing a 1000-page big-book catalogue and a website. Is that right?

TM: Yes. Absolutely.

MM: As I recall from our conversation, if someone had the printouts from your mainframe - you physically tacked a piece of green bar up on the wall which somebody then transcribed into a spreadsheet.

TM: And if an artefact like that didn't work well, then we took a picture of something. Remember when you were moving paper around, a lot of times it was, 'Put something in a bin', or, 'Take it to this location'. If we felt it couldn't be described very well, we'd take a picture of it and put the picture up on the wall, too.

MM: If 'Sneaker ware' was involved, where someone had to physically move a file from one person to another, you had photographs of the individuals and a string connecting the two individuals?

TM: We had yarn. We had different types of colored tape that we would use. We had different colored starbursts that meant different things. We identified pain points, as well, during this process.

A big red star meant, 'Here's an issue'. A Pain Point.

MM: How did you call out defects?

TM: In much the same way. But again remember - we were not trying to solve any problems, yet. We were only identifying them. MM: I can't overstate the importance of what you just said. Many people make the mistake of going in to an organization with a 'change mindset'. 'Here's how we're going to change this. Here's how we're going to change that'.

That naturally produces all kinds of pushback and resistance among stakeholders.

TM: And resentment.

MM: So you simply got everyone to acknowledge, 'Here's how we do our catalogue'. With the idea of really coming to understand if not appreciate exactly the kind of frustration each stakeholder had experienced in this process.

TM: And you know, it's funny you say that. Actually, at three points during the process, we had everyone come up to the board and sign it, that they agreed with everything that was up on the board.

The first time was after we defined the current process. Everybody agreed. Another time, when we defined an interim process that we felt we could implement without the software solution. So, we saw some immediate benefits from defining the process. Then the third sign-off was when everybody agreed to the 'new optimal process', which would include the database publishing system.

MM: Fabulous.

What you have just described, Tom, is the workflow map in the War Room. It became a visual contract.

TM: Absolutely. Yes. That's what it was. MM: What made it easy to sign, is that the stakeholders participated wholly in defining the current state, as well as the interim state in terms of, 'Here's what we could do to make things better without having to automate anything'. TM: Correct.

MM: As you begin to create this visual roadmap, people naturally begin to argue about who was responsible for what. Or how things got done.

Can you take us through a couple of those scenarios, and how they resolved? 
TM: Let me step back just briefly and talk about a little bit of the hierarchy we had at Hubert. I think that that had an effect on those types of situations.

MM: Sure.

TM: At Hubert, they had a VP of Organizational Development. He was a person who reported to the president but did not have any structure under him. He was a changemanagement guru.

Because he reported only to the president and had basically no agenda, he could work across departments and not appear to be persuaded by one or the other.

Additionally, this man was trained to facilitate meetings. He was really good at what Peter Block would call the 'what' question. That is, 'If you ask a "what" question, you're going to get a whole lot more different types of responses than when you ask a "why" question'.

If you ask, 'why' - you're challenging somebody. However, if you're asking 'what' you're asking them to explain what it is that they need to tell you. That was something that he was a master at doing. He was able to allow people to speak freely, but also was able to get them focused on the right path together - without creating a lot of disturbances.

That said, there are some people in every organization that are going to create disturbances. You have to address those - and sometimes, that means that there's somebody that's going to have to go. And at Hubert, there was. There was a person that had to go.

At Central, they were fortunate to not have it to that degree. But, there are always those that latch on to change and those that desperately try to avoid it.

MM: Before I come back to how companies can augment or bring in that capability as a function of perhaps an external consultant which would probably be a second, or less-desirable, option ...

Could you take us through Hubert's toolkit of change management?

TM: The key was out "Right up front" Masstra. MM: What does that mean?

TM: It is making sure that you do things right the first time, and, therefore, you don't have to worry about it later. That lives in several different areas. It can live as a whole - meaning if we hadn't done the research and the white paper and all that stuff upfront, would we've been as successful?

But you can take it down to the minutia, too. That is, Hubert identified during the current process that there was a maximum of seven times, where a price could be entered into the system. Now, that seven times didn't happen all the time - but it wasn't unusual for a price to be entered at least four times into the system at some point.

MM: That means, manual data entry of a pricing data four or five times against what? 50000 SKUs?

TM: More than that. Yes.

So if you think about the opportunity for error there, and we're talking about entering where it could be somebody writing it down on a sheet of paper. That's 'entry'. Right? Or putting it into a spreadsheet and not into a database. That's entry. Putting it into one database and then another database. That's two entries.

That's what I'm talking about - how that is looked at. The idea was, 'Let's find the point where it should be entered - the right point upfront. Let's find out where it should be entered, who's responsible for that entry, and when you enter it - make sure you do it right'. MM: Right.

So I want to circle back a little bit later on the notion of training as a part of the overall change-management process.

But for now, you had this change management process as you've nicely outlined it.

You had an individual - in this case, a trained psychologist - as I recall TM: Yes. He was PhD in Psychology. $\mathbf{M M}$ : His whole function in the organization was to represent what is best for the company as a whole. He really facilitated the communication, interaction and collaboration among various stakeholders, to more deeply or more closely align with what's best for everyone - including what's best for the corporation.

TM: Yes. And this was especially valuable on large processes like this one.

But he also did some train-the-trainer type of things. Because it's a cultural paradigm. Yes. So, the idea was that if everyone in the 
company had this skill-set, then it would be a better place to work.

So part of his job, too, was to train people how to be like that, as well. So therefore ...

Let's say there is a process that involved Sales and Marketing. Maybe a person in the Warehouse was trained to do it. Maybe the Warehouse person would facilitate that meeting, because he did not have an agenda between Sales and Marketing.

But if it were a big process across multidepartments - which this one was - then he would be involved with something that big.

MM: Most companies do not have a structured, defined, repeatable change-management organizational transformation process in place.

TM: I've never seen one other than Hubert. MM: Exactly.

That makes change so wrenching and difficult, expensive and problematic. Because inevitably, change means that people have to get out of their comfort zone and get out of their daily routines and habits, and do what is new, uncomfortable and probably prone to criticism.

TM: Yes.

MM: So one of the principles of an innovation culture or an ingenuity culture is that you have in place a change-management process that you invoke whenever you need to accommodate an innovation.

TM: Yes. That would be an excellent model for any company.

Perfect.

MM: It isn't innovation at the top, but it's innovation from the bottom-up. The real, 'Here's how we can really make this process sing', doesn't come from a top-down declaration or fiat, but it comes bottom-up from the actual users - the stakeholders in the workflow.

They're closest to what actually has to get done, and specifically to where the pain is. TM: That's absolutely true. But the caveat there is that the upper management - even though it's not their idea - their support has to happen. It has to.

MM: However, most change processes run into trouble when it simply becomes a top-down mandate, as opposed to a bottom-up collaboration and discovery of, 'What's the best way of doing this one piece', while maintaining the context of the whole change.

TM: Absolutely.
MM: Great.

One of the other things that you had done there at Hubert that was most extraordinary was ... As you had developed this end-to-end visual depiction of the entire process, it became clear that there were a couple of principles you could apply into making that better.

TM: Yes.

MM: Let me unpack it a little bit.

TM: Okay.

MM: First, you had this wonderful, messy, warts-and-all visual depiction of the entire end-to-end process.

TM: Yes.

MM: Everyone signed off on it, quite literally. Everyone said, 'Yes. That's my contract with reality'.

TM: Yes.

MM: In the process of doing that, you dissolved all or most resistance to change.

TM: Right. When we came out of that, everybody in that room was eager for the next step. Not afraid.

MM: First of all, they were aghast about how it is they had such a big mess on their hands. That was the first thing. Right?

TM: Yes. They couldn't believe it.

MM: That then gave rise to this rocket of desire to make it better. And there was a visual, persistent object on the wall in terms of how to have a meaningful, cogent, logical conversation with other stakeholders about how to facilitate the change.

TM: Correct.

MM: So in essence, as a function of having this physical map, you could future-proof a change without actually having to make it.

By doing these collaborative mental simulations, you could then quickly deduce what would be changes that we could do now. And changes that you'd want to make if we had an automated, online system.

\section{TM: Correct.}

There were two kinds of interim steps. One was when we saw all the errors of our ways in the current process. There were things that we could do the week after we said, 'Okay. We've identified it. Let's change these'.

MM: In the course of defining and getting it right upfront, the other things you identified were where in the process that should optimally 
occur, who in the process would now be accountable for data entry, and the quality assurance for what got entered.

TM: Yes.

MM: Now as a general principle, this goes back to Peter Drucker's notion of Knowledge Worker Productivity. Where he defines it as, 'How quickly can I ask for information from another person?' And/or, 'How quickly can I provide information to another person', with a specified time, place and format?

So in essence, what you're doing here is, you're optimizing the productivity of individuals in the workflow by - first of all - identifying who my upstream providers of information are, and who my downstream recipients are of good, high-quality information for which I am responsible.

TM: Yes.

MM: Fabulous.

So, then as you begin to understand who contributes what - I imagine this produced many conversations around conflicts or arguments or confusions in terms of, historically, who had been responsible for what.

TM: Yes.

I can talk a little bit to that.

MM: Please.

TM: One of the things that happened was there was distrust. That was probably the largest obstacle we had. For so long, people had dealt with other peoples' mistakes that they didn't trust the other people to get things done right upfront.

Going back to the accountability issue, when the process was optimized, it was drilled into the people that - 'If this is your only chance to do this, then you have to do it right. Because nobody's going to be checking your work any longer'.

MM: Yes.

TM: That's where we came into some obstacles. Because people would say, 'No. I have to see that again. I don't trust that these people are going to do their jobs correctly'.

MM: Now you've gotten to the root cause of why most change initiatives fail.

TM: Yes. And that's why someone who has this change-management, psychological understanding and can facilitate is an important vehicle. He was able to identify those fears.
MM: For what they are.

Legitimate, fact-based, historical references that individuals were projecting into the future, with a certain amount of cynical realism.

TM: Absolutely. 'Cynical', is a very good word to use.

MM: Where 'cynicism', is simply the belief that the past will repeat itself.

TM: What's past is prologue.

MM: Right.

So part of the change-management innovation leadership was - first of all - not only to deal with the structure - that is ... the end-to-end visual depiction - but was really to address these deeply seated, felt beliefs in terms of, 'I don't trust the process'.

So part of the innovation-leadership process then entails building new trust in the proposed system.

TM: Building trust and - as this person used to always say - eliminating fears.

MM: Yes.

TM: It's kind of the same thing, but ...

Fear-based activity is rampant during these processes.

MM: Absolutely.

This gets to another underlying issue that you've set up beautifully, here.

Most businesses tend to be what I call, 'execution systems'. Whether you have an annual plan or not, generally, you'll have goals, roles and responsibilities as they're related to my 'executing against plan'. Even if the execution is, 'I need to get so many pages of content published today'. Right?

TM: Okay.

MM: In the context of 'execution', there's no mental space. There's no freedom to change.

Usually you're running full out executing to plan. So you could say that change and the special class of change - innovation - become sand in the gears of execution. That fundamentally most companies have constituted themselves as a 'change-resistant execution system'.

TM: Not on purpose, I don't think.

MM: No. We were so busy trying to survive and grow and maintain our profitability - those are all exceptional mindsets. So, the baby that got tossed out with the bathwater was, "We gave up. We traded growth and security for our ability to change and adapt'. 
So now, we're at the point where we're saying, 'No'. Because the world is changing so rapidly - because technologies and innovations change fundamentally how we find and serve customers so rapidly - we now must bring into our execution system a new set of muscles.

Change-management organizational transformation - which I'm now summarizing as innovation leadership.

Specifically, as it relates to a context of change, in an execution system, everyone knows - for the most part - who they are as a contributor to workflow, and what outputs they owe to whom, and who owes me. What kind of good inputs.

TM: Right.

MM: But in the context of change, there's no accountability. There isn't any role clarity around 'who owes what, delivered how, by what criteria of satisfaction or quality'.

So you could say another root cause of change resistance is that there's no accountability in a context of change. No one knows what to produce, for whom, in a change environment.

That was what was so brilliant about your map. About this end-to-end visual depiction. Right? TM: Yes.

MM: It became clear in terms of the current state, exactly who does what for whom. That also then stimulated a conversation called, 'in the future', interim. Or, idealized optimum of, 'Who owes what?'

You got everyone to agree that, 'Yes. That would actually work for me'.

TM: Yes.

MM: So part of addressing fear-based behavior was replacing it with optimistic, forward-looking, pictures and images and experiences - as grounded by this visual depiction of the interim workflow, as well as the optimized workflow.

TM: Yes.

MM: Great.

One of the other things that you'd shared with me, Tom, was that Hubert was unusual in a couple of ways. Not least of which was that they practice activity-based accounting. TM: Yes.

MM: For the purpose of our readers, could you explain 'activity-based accounting'? And how that clarified the cost of the current-state operation?

TM: Activity-based costing at Hubert involved an exercise that was completed every year that depicted the different activities cross-referenced with percentage of time spent on those activities for each position in the company.

Then, as an additional caveat, there was an activity that was called 'IT Involvement'. You could gauge how much technology needs were being used. Another piece of that, of course, was how much building space you used and attach value to that.

On a yearly basis, we would look at the different activities, define different numbers to those and then the accounting group would take those percentages - knowing what the overhead was, and additionally knowing what money you spent. For instance, in the catalogue piece, you spent so many millions of dollars to print the catalogue and to buy the paper. So those pieces were applied to that activity, as well.

Then you were able to say, 'Well, if it takes us this much time activity-wise to produce a catalogue and we need to produce another catalogue, how much activity would that take'?

Then, apply that to the time savings that you would anticipate to enhance that or to decrease that activity - based on a particular software like database publishing. Then you have a 'soft dollar ROI'.

However, as everybody knows, once you commit to a soft-dollar ROI, it becomes a hard-dollar ROI.

MM: So when you looked at this visual depiction and then started to create an interim optimized workflow - at what point did you start applying activity-based costing to the workflow?

TM: Actually, the activity-based costing came after that. I'll tell you why. It came when there was recognition of how much indeed the new process was going to be able to change the workflow.

MM: So, let's use this as an opportunity to shift into the optimized workflow.

TM: Sure.

MM: Over the course of 9 months in this War Room, you developed a visual end-to-end depiction of the messy current-state operation. TM: Yes.

MM: Out of this precipitated a number of interim changes that you could make, because they were easy, self-evident and everyone said, 'Let's do it'. 
TM: Yes.

MM: Then you developed a new workflow, an optimized workflow, embracing some core principles - one of which you identified as 'Right upfront'.

MM: And enter data once and only once.

TM: Yes. Enter once, publish many times. MM: Yes.

And 'stay online'. So, as much as possible, keep the work online as opposed to going offline in an analogue or physical work activity. Is that right?

TM: Yes. Although I think you might cover accountability and enabling within the 'right upfront', the enabling thing was kind of a sticky point, there. It was important for people to do what we called 'Staying out of somebody else's backyard'.

You can't do their job for them. If they're going to fail, they're going to fail.

MM: Yes.

Fabulous. So it's kind of, 'You're accountable for your work, and you're not your brother's keeper'. Or - what's the psychological term? 'Enabler'. What do they call that when you enable somebody else's addiction or bad behavior?'

TM: We call them 'enablers'.

MM: Enablers. Okay.

So, 'Stand on your own two feet and get your job done', is another core principle.

TM: Right. That doesn't mean you can't be helpful. But you can't do somebody else's job for them.

MM: Perfect.

So that was your principle around enabling. No more enabling bad behavior or enabling shoddy work.

TM: Yes.

MM: You're accountable for producing highquality work now in this increasingly transparent self-evidently accountable workflow process.

TM: Right. Because people recognize that if nobody else is doing this ...

MM: It ain't gonna get done.

TM: Right. You can't hide any more.

MM: So, this has actually two dimensions to it. You just described the downside of it. That is fear of recrimination and ridicule and maybe some lost jobs.

But the upside of it is, I am now an acknowledged contributor. I'm needed. I make a difference. I contribute here in a very direct and now transparent and accountable way.

TM: Yes. We are dependent on you.

MM: Yes. And we are inter-dependent in a sense.

That sense of being part of a team in and of itself provides a sustainable motivation for getting it right upfront.

TM: Yes.

MM: The next thing I'd like you to talk to is the optimized workflow.

With these basic principles of accountability and no enabling bad behavior or sloppy work. Staying online. Getting it right upfront.

With that set of principles, your current-state process, as I recall from our conversation entailed about 300 or so discrete steps.

Is that right?

TM: That is correct. Three hundred individual steps.

MM: Then how did you start to develop the optimized future-state capability?

TM: Well, as you mentioned - the visual representation on the wall. We kind of created, after we had all of the artefacts out there, we either took pictures or put them into a document. We reduced them so that they could fit on half of that wall. Then we drew a line under that.

The top of the wall was the current. The 'current' being with a few modifications that we felt we could implement right away.

Then we drew a line.

On the bottom, we started the new process. 'What do we do now? What is the process that we should lead with? Look. You're doing this at the backend, and we know that there's pain back there. We want to move this up into the process'.

MM: So, for example, there were two things that I wanted you to just quickly speak to. One was the building of the index in the back, the subject index in the back. And, two, the pageprofit analysis.

TM: Okay.

MM: So, describe both of those in terms of pain points. And, ideally, how you'd want to resolve them.

TM: Sure.

Let's talk about the index, first of all. In a 900-page catalogue, creating an index can be quite the chore. It typically happens at the end of the production cycle. 
So there was like a 2 -week period at the very end of the production cycle, where 15-20 people sequestered themselves into a room and basically called out names and told what page number those particular items were on. That's how the index was built.

Again, you're talking to $10-15$ people for 8 hours a day, for 2 weeks. That's a lot of man-hours.

MM: Yes. That's 30 man-weeks.

TM: It was understood that it had to be done.

So, we recognized with database publishing how electronically that information is captured within the database, and - through a simple export - that same result can be more accurately and quickly exported within a matter of 2 hours.

MM: So, essentially, you freed up 3/5 of a fulltime equivalent.

TM: Yes. But more importantly, we reduced the cycle time by 2 weeks.

MM: Right. Perfect.

So take us through what the merchandiser did with page-profit analysis.

TM: Yes.

One of the things that we saw immediately that was advantageous when you think about the fact that all it is - is data. You used to look at a Quark or InDesign page - and say, 'Okay. That's a design page. Type in the information. Import a picture'.

Once the mindset or paradigm shift happened, people started looking at that as data. Then you started saying, 'You know what? There's other data we might want to be able to look at on this page, after we've already sent the page to the printer'.

If you can populate data on a page in a price table, does there have to be a price? No.

It could be the amount of sales for that particular SKU or that particular product grouping. Or it could be the number of units that were sold that year. All you have to do is change the data field that it's pulling to the page. MM: In the current state, Tom, you had merchandisers that would own a particular category or categories of product. With a felttip pen, they overwrote on a print catalogue page the quarter or the beginning inventory position, end inventory position, items sold, gross revenues.

TM: Sales - gross profits.
And they would actually be looking at a green bar, writing information into a catalogue sometimes using the spreadsheet on their screen to compile data if they needed to compile it. Because the green bar wouldn't do that.

Each of the product managers would be doing this. So there were five product managers that would spend 2-4 weeks in every cycle populating their pages in their catalogue.

All of the product managers wanted to have all of the information, so they'd switch books and they'd mark up somebody else's book until all five product managers had all five master books marked up with that information - hand written.

MM: So the idea then in the future-state is 'Wouldn't it be cool if we took a PDF or the InDesign document that had the 900- or 1000page document and simply did an overlay?' A data overlay from the database of beginning inventory position - end inventory position gross revenues - profits - returns. Simply just published directly - almost as a transparency or an overlay to the actual thing on the page.

TM: Absolutely. That's exactly what we did. We could do that in the course of a weekend. MM: Yes.

Another aspect of that is that merchandisers begin to understand and correlate. There are certain particular presentations or configurations of products that produce a 'lift', in terms of increased sales. And there are particular parts of the page that tend to suppress sales in terms of, 'For whatever reason'.

If I put that product here, I get a 3 per cent bump. If I put that same product over here, then I take a 5 per cent hit.

TM: Yes. There are additional modules that you can get that even do more forecasting than those types of simple analyses, too.

MM: Such as?

TM: It'll say, 'If you put it in the upper righthand quarter or the lower left-hand corner'. Or, 'Is it on the first page of the section or is it on the cover, too?' 'Is it on the back cover? Is it on the inside front cover?' 'Are you presenting it on the web differently? Are you even presenting it on the web?'

There are lots of different ways to look at that type of data.

MM: So then, as you develop the future-state capability, you started to really define work cells. 
That is to say, 'individuals'. So you take Sally, who is a merchandiser, and you say, 'Okay. Sally sits here in the workflow'. Right? TM: Yes.

MM: So take us through how you begin to develop a visual depiction of Sally's engagement with the workflow vis-à-vis an online get-itright-upfront workflow process.

TM: I see what you're saying.

One of the things that we did that we felt was very important was - and this was typical with all the vendors that we talked to - they wanted to do their training based on their features of the software. Is this where you're headed? Is this what you were thinking about wanting to get at?

MM: Yes.

TM: The classic analogy is this. Let's say you're working in Microsoft Excel. Somebody tells you they want you to write a formula.

Well, how are you going to write that formula? You could type it in. You could click on cells. You could do one of their automated things. There are probably about eight different ways you can write a formula in Excel. Well, with these database publishing solutions, there are probably about eight different ways you could create a product manager's role.

But what we did was - we had a core team. We learned the features. We said, 'Okay. We're going to populate the database. We're going to have our information in there. We're then going to create a training manual using our information, based on what we feel the optimal way to use that system is'.

That's what we trained on.

MM: Fabulous.

So before you actually configure the software much less buy the software - you create a training module for an operator.

TM: Right.

MM: In this training module, you describe really the performance of that job. That is a job function, which I call the work cell. You describe that work cell as a trainable, repeatable process ... TM: Absolutely.

MM: In the course of doing that, you documented for Sally what her job looks like and using the training manual to really mock up the user experience.

TM: And making it real for her. Because when she's looking at the data and the examples in the screenshots, it has information that she's familiar with.

MM: Right.

So this also then entails you mocking up screenshots, because that's what you would need in the training manual. Is that right?

TM: Correct.

$\mathbf{M M}$ : So in essence, what you did was to design at the level of business process, workflow and accountability. You defined the user experience not just as screenshots, but also as a user manual.

TM: Yes.

MM: Brilliant!

So then, that gave you an optimized workflow that you could visually depict - probably using pretty standard workflow diagrams. Right?

TM: Yes.

MM: What type of methodology did you use to visually depict the new ones? Swim lanes or any particular methodology you used there?

TM: Give me an example of where you're headed. I'm not sure that I understand.

MM: You said in the War Room, you drew a line down the middle.

TM: Right.

MM: What was physically below the line, in terms of the optimized workflow?

TM: Oh - I see what you're saying.

MM: If we walked into the room, what would I see?

TM: Sometimes there would be a written step. Sometimes it would be a screenshot with the new data. Sometimes it would be a screenshot of a directory.

MM: So these are basically the artefacts that went into the user manuals.

TM: Correct. That's exactly what they were. Yes.

MM: Okay.

So now, in the course of then developing this optimized workflow - creating it one screenshot at a time.

TM: Yes.

MM: In the course of developing these screenshots, you had the operator - the intended operator - come in and interact with you and ultimately say, 'Yes. That's what I want my screen to look like'.

TM: Partly.

Remember that we really hadn't chosen the vendor, yet at that point. There were basically 
mockups that were just done in Excel that showed a basic idea of what it would look like from a data standpoint. But not what it would look like visually in the application.

MM: Perfect!

So you developed the wire frame or the exposed data model for that particular screen or activity?

TM: Yes.

MM: Perfect.

Then, how long did it take you to develop that idealized workflow model?

TM: I was trying to think about that - how we broke that down. It was 9 months for the total. My guess is that it was like 6 months for the current workflow and 3 months for the optimized.

MM: Then at that point, you applied activitybased accounting. We already identified that the current-state workflow entailed 300 steps. How many steps did the new, enhanced workflow - entail?

TM: 200.

MM: So clearly, a third of the steps went away? TM: Absolutely.

MM: Now activity-based accounting allowed you to calculate with fairly good accuracy the economic value of eliminating those 100 steps.

TM: That's correct.

MM: And do you recall what that was?

TM: I couldn't put my finger right on that number, but I know it was more than the cost of the software.

MM: Right.

So in the course of that, you also were able to estimate gains in cycle time. Is that right?

TM: Yes. In fact, that was a major thrust. We knew that we wanted to produce the catalogue twice. At that point, we were only producing it once a year.

MM: So basically, you were going to be able to double your cycle time. Not double, but cut it in half.

TM: Cut it in half.

MM: Fabulous.

So once you identified that that was a change worth making, the pain associated with the gain would be that there were 100 steps missing with economic value of $\$ 500000$ or 400000 . And halving the cycle time would produce incremental sales - as a function of being able to get refreshed content out there.

TM: Yes.

MM: The other benefit is that now you had your website and your catalogue more closely synchronized.

TM: Right.

MM: So you didn't have one price one place and another in another.

TM: Right.

MM: That would reduce a certain number of customer service cycles. Or discounts that were more like 'make-goods', as a function of satisfying the customer. Right?

TM: Right.

MM: Then you said, 'Okay. Let's go find vendors, then, who can automate this new idealized workflow'.

TM: Yes. Well, you know, a lot of that was going on simultaneously, too. By then, I knew who the vendors were.

MM: Right.

TM: Yes.

MM: As I recall, you started off with 15 or so vendors, in terms of your not short list, but your medium list. Right?

TM: Right. So I probably looked at 100, and we cut it down to 15 for a more thorough review.

MM: Great.

At that point, as I recall, Tom - you brought them in and showed them the current and future states. You asked them to speak to how they would automate the future state. Is that right?

TM: We only brought in four.

MM: Yes.

TM: That's correct. We sat them down in the room after they gave their presentation and said, 'Okay. Here's our flow. Now we're going to leave you here for a while. When we come back, we want you to present to us how you can affect our flow'. So we really put them on the spot.

MM: Not just 'affect our flow', but implement it. TM: Implement your solution. How is your solution going to integrate with our flow? MM: So, what came out of that?

TM: Well, some things that we were able to gauge. To say, 'These people are telling us the truth. These people speak our language and understand what we do. These people are not trying to fit a round peg into a square hole'. 
For instance, one group would say, 'Oh, yes. We can do all of that. We'll just make it work'. That's not what we wanted to hear. We wanted to hear the truth.

One person would say, 'You know what? You've got a pretty good solution here. We can automate this and automate this and automate this. We're not sure about this automation here. You may have to keep this as a manual process for a while, until a new version comes out. Or we can implement it as a part of our software'.

Then there were people that would talk about heuristic attitudes and speak a different language. We knew that they didn't understand the catalogue business. So when we started talking to people that not only talked our language and understood what product groupings and SKUs were - and making sure that there was an image that could be saved in a directory as a JPG and the high-res image in a similar place. We understood that they knew what they were talking about.

So, it was almost an interview, as well. MM: Yes. And then you selected a vendor. TM: Well, we actually went through two stages of that. We had them back. We actually took some partial data and then presented to us. We cut it down to two, then each of those came back and presented us with our data. MM: We can edit this out later, but can you share with us the four that made the interim cut and the final two?

TM: Sure.

The final four were Banta ...

MM: That's now part of WACW Corp, as I recall. And it's called B-Media, as I recall. Right? TM: Correct. Yes. B-Media.

Then the other one was A2I. Now owned by SAP.

Cascade was one of the final two. Which later became 'Engage'. And I don't believe they're in business any more.

MM: Right.

TM: And then Pindar - who did get the job. MM: Right.

Then as you selected and went through more of a formal RFP process that entailed them taking data and mocking it up in their system ... TM: Yes. That's when they quoted on the system, as well.

MM: So you had vendors quoting on how to automate your workflow, as opposed to simply how to install their code and then shoehorn existing current-state users to their system?

TM: Correct.

MM: Fabulous.

As a function of having created the user manuals, did you then have the vendor basically rewrite or augment the manuals? Take us through that.

TM: Yes.

We had additional meetings, after we chose the vendor. We had a meeting where they went through how they normally train. We said, 'Well, that's very nice. But here's how we want you to train us'.

It was more focused, but just as intense. In other words, they had a certain number of days that they had allotted, to cover every feature. We said, 'Well, we don't want to cover every feature, because we're never going to use these. So we want you to focus more intensely on these particular features here - based on the particular jobs that are out there'.

MM: You just introduced another little gem.

TM: Okay.

MM: Typically, enterprise-class systems will have anywhere from 30 to 50000 function points. Where each function points represents an engineered set of code. Right?

TM: Right.

MM: When you deploy an enterprise system in an organization such as yours, out of those 30 or 50000 function points, you may ultimately only activate 500 or 600 of them.

Any one power user may only really use 80-100 of them. A typical user in a particular part of the workflow may only use 20 or 30 of those function points. Another way of saying that is that if you take the 500-700 function points, that's barely 1 per cent. Right? Actually, a tenth of 1 per cent of the entire functionality of a 30000 or 50000 function-point suite.

This kind of gets to the silliness of these magic quadrants, which you see from these various research firms. Where you see, 'Completeness of vision', and the 'Ability to execute'. Because the completeness of vision is those 50000 function points -99.99 per cent of them, which are useless.

So really, you're saying that as a function of doing all of this work upfront, we were able to identify the most choice function points that deliver economic value. 
So you said, 'Okay. Our baseline is economic value'. Then the offset of that would be time -to value. How quickly can we unlock the value of those particular function points? You've identified the critical point in time -to value - which was an end-to-end visual depiction of the future-state training manuals, with individuals already up-to-speed mentally and experientially - on the new workflow.

TM: Yes.

MM: Then you had the vendors train operators to the specific workflows as defined by initially - the rough draft user manual.

TM: Yes.

So we wrote our own training manual. MM: Yes. Fabulous.

This gets back to this whole notion of process maturity, where from the get-go you started off with a documented workflow, and then built training into the workflow.

TM: Yes.

Well, training was definitely a part of the change-management.

MM: It's also a part of the mindset called 'There's no such thing here any more as an undocumented work'. And documented work without training is only half the solution.

TM: Yes.

MM: Great.

In the few remaining minutes that we have as I recall, you installed your team - installed the software on a Saturday - right?

TM: Yes.

MM: Take us through the start-up process.

TM: Oh, boy.
Originally, I think, we were going to do a pilot. But since we were working on live data, there were only a few minor mess-ups in the first 2 weeks, and we decided to keep everything live. I believe that within 60 days, we were already producing new catalogues. I forget the exact, right now, Michael. But it was one of those things where you go, 'Okay. We're going to take a short step', and we ended up running. MM: Yes.

So as I recall from our previous conversation, you installed the software on a Saturday. You started working on live data 4 days later. And as you began to work on live data, you'd use that as an opportunity to kind of do the final quality assurance and training, which took another 4 or 5 days.

TM: Yes.

MM: In 2 weeks, you pretty much had operators in workflows producing commercial product.

TM: They were producing. They were in production flow.

\section{MM: Yes.}

So within 2 weeks, they were in production workflow, and it took another 40 or 45 days or so to completely make the shift.

TM: Yes. I don't know that we ever thought about not shifting.

MM: Well, now - but I mean the hand-over process was relatively painless and fast.

TM: Yes. I think that we ran into some obstacles the first month or two, but nothing that was a showstopper.

MM: Excellent. Thanks so much.

TM: Thank you, Michael. 